\title{
Research On The Identification And Evaluation Of Supply Chain Finance Credit Risk
}

\author{
Yinuo Liu, ${ }^{1, *}$ \\ ${ }^{1}$ School of Business Administration, Northeastern University, Shenyang, Liaoning 10000, China
}

\begin{abstract}
Narrow financing channels and high costs have gradually become the main factors restricting the development of small and medium-sized enterprises. The break of the capital chain will restrict the development of the overall supply chain. The emergence of supply chain finance has brought good news for solving the problem of limited capital of small and medium-sized enterprises. However, affected by many factors such as the imperfection of the existing regulatory system, the inefficiency of the credit rating work of financial institutions, and the low moral standards of supply chain member companies, financial institutions bear huge credit risks. Based on the current research of supply chain financial credit risk, this paper analyzes the causes and characteristics of supply chain financial credit risk, finds out the problems and their causes in the identification and evaluation of supply chain financial credit risk, and how to identify and effectively identify and analyze the supply chain financial credit risk in a more timely and effective manner. It is expected to provide reference for financial institutions to strengthen the financial credit risk management of supply chain.
\end{abstract}

\section{Introduction}

\subsection{Research background}

In recent years, the number of small and medium-sized enterprises in China has been increasing, and the shortage of funds has become a key factor restricting the development of small and medium-sized enterprises. In order to support the development of small and medium enterprises, the state has actively implemented a series of related policies such as inclusive finance and encouraged the improvement of the credit reporting system for small and medium enterprises. Supply chain finance is an important manifestation of inclusive finance.

Loan balance in the field of inclusive finance (Unit: trillion yuan)

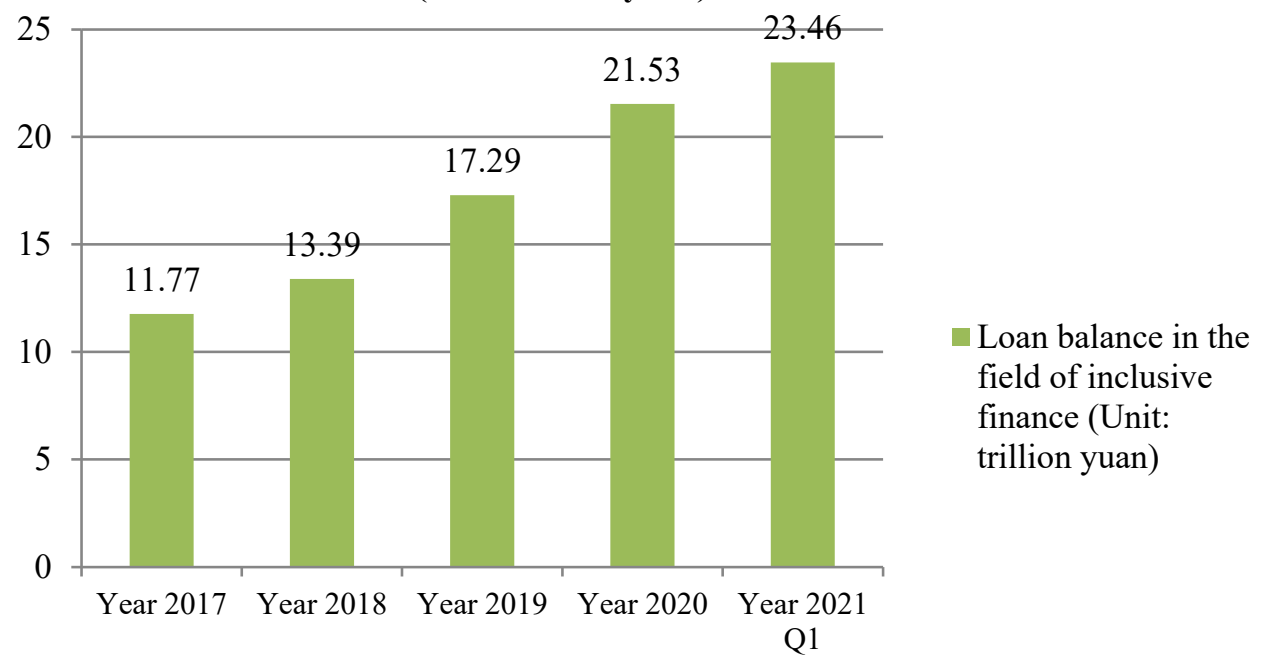

Fig. 1. Loan balance in the field of inclusive finance

According to statistics, the balance of loans in the inclusive finance sector in China has increased year by year. As of the first quarter of 2021, the balance of loans in the renminbi inclusive finance sector has reached 
23.46 trillion yuan, indicating that financial institutions have actively responded to policy calls and strengthened their efforts in key areas of inclusive finance. financial support.

The development of supply chain finance not only provides new ways for small and medium enterprises to raise funds, but also expands the business areas of financial institutions and provides new profit growth points. However, competition in the financial industry is fierce. In order to increase business volume, some banks are willing to bear huge risks, granting substandard companies or excessively high credit lines, and the lack of financial institutions' own risk management systems can easily lead to financial institutions' economic development. loss. Take Bank of China as an example. At the end of 2020, the group's total non-performing loans reached 207.273 billion yuan.

Total non-performing loans of Bank of China Group (Unit: 100 million yuan)

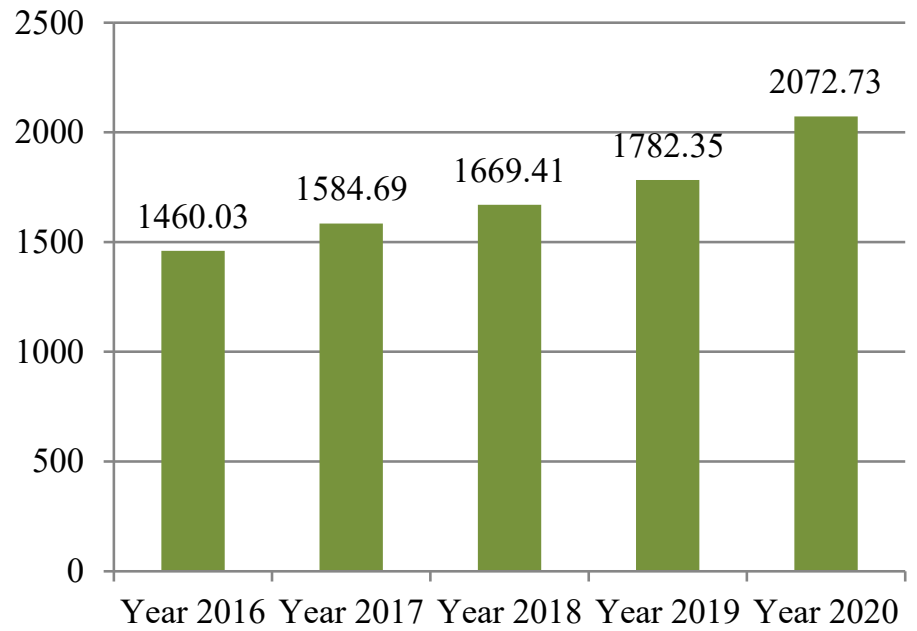

Total nonperforming loans of Bank of China Group(Unit: 100 million yuan)

Fig.2. Total non-performing loans of Bank of China Group

Therefore, strengthening the financial risk management of the supply chain has become the focus of financial institutions. Supply chain financial risks include operational risk, credit risk, trade risk, etc. Various risks interact and influence each other. This article mainly studies supply chain financial credit risk.

\subsection{Research status and significance}

Supply chain financial credit risk refers to the possibility that the financial institution cannot perform its obligations in accordance with the pre-agreed conditions, that is, the default of the financial institution causes the actual income of the financial institution to deviate from the expected income, or the time for the realization of the income to deviate. Halliksa (2002) [1] pointed out that supply chain risks are caused by uncertain factors, and the closer each member company is, the more vulnerable it is. Yang Yanzhong (2007) [2] pointed out that strengthening internal control can effectively reduce the financial credit risk of the supply chain. Fan Shengjie (2012) [3] pointed out that the key to supply chain financial risk management is credit risk, so optimizing logistics financial operations is crucial. Huang Jingsi, Song He, Song Xinhong (2014) [4] pointed out that when analyzing the risks of the supply chain system, it is necessary to consider not only the risks from the enterprise itself, but also the characteristics of supply chain operations and the external environment. Fan Fangzhi and Su Guoqiang (2017) [5] pointed out that the financial credit risk of supply chain finance mainly comes from small and medium-sized enterprises that have obtained financing. Therefore, current research mainly focuses on the evaluation of the causes and influencing factors of supply chain financial credit risks, and how to identify and evaluate credit risks in a timely and effective manner has become an urgent problem for financial institutions to solve. This article first sorts out and summarizes the causes and characteristics of supply chain finance credit risk, and points out that the existing risk management system of financial institutions cannot identify and evaluate supply chain finance credit risks in a timely and accurate manner. Combining its causes, it focuses on how to fully identify and evaluate supply chain finance. Credit risk recommendations. The research significance of this article is to enrich the existing risk assessment system and emphasize the importance of non-financial indicators; at the practical level, it puts forward constructive opinions and optimizes credit risk identification in response to the problems of financial institutions that cannot effectively identify and evaluate supply chain financial credit risks. The evaluation mechanism helps financial institutions find potential risk points in time, respond in time, and reduce losses. 


\section{Characteristics of Supply Chain Finance Credit Risk}

\subsection{Strong conductivity}

Li Guangrong, Guan Yinxue, Huang Ying (2020) [6] believes that supply chain finance relies on the supply chain, and the member companies in the chain are interdependent and cannot be separated. If problems occur in any link, the so-called And moving the whole body" may lead to the collapse of the entire supply chain. When there is a problem in an upstream company, even a negligible impact will continue to accumulate as the supply chain is passed down, affecting related downstream companies, and ultimately lead to the destruction of the entire chain. When a downstream company has a problem, it will be counterproductive to the upper level and affect The supply of funds throughout the chain will also have a huge impact. Therefore, each link in the chain does not only act on itself, and its impact is so great that it endangers the entire chain.

\subsection{High information security requirements}

Information exchange runs through the supply chain finance, especially the current Internet supply chain finance is more dependent on big data, cloud computing and other network information technologies. The higher the level of information sharing between upstream and downstream enterprises in the supply chain, and between enterprises and commercial banks Come higher. This requires a high degree of completeness and authenticity of information. If there is false information, such false signals will spread along the supply chain, endangering more companies. Nowadays, cases of hackers attacking network systems are not uncommon. Network information security incidents occur frequently. Many information systems themselves are extremely unstable. Many companies are discouraged from entering information that is truly beneficial to supply chain operations. Supply chain finance puts forward extremely high requirements for information security.

\subsection{Many factors affecting credit risk}

For traditional financing services, financial institutions only contact a single enterprise point-to-point. As long as the effective operation of the enterprise is ensured and the market value of the collateral is sufficient to make up for the losses that the financial institution may suffer, it is feasible to provide financial services. Supply chain finance needs to consider all factors that may affect the member companies of the supply chain. Even if a certain risk factor only affects a small part of the supply chain, it may have an impact on the operation of the supply chain, and credit risks may arise. Therefore, various factors such as natural disasters, government policies, and corporate structures will affect the entire supply chain.

\subsection{The risk spreads quickly and has a big impact}

Chu Xuejian and Li Pinfei (2017) [7] believe that risk diffusion is divided into early stage, middle stage and late stage, and it enters the outbreak stage in the middle stage. The supply chain is not a simple linear structure. It is a network formed by various enterprises that are interconnected and interdependent. An enterprise has risks, and it will soon be passed horizontally and vertically through this network to other enterprises, and even other industries. With the optimization of the supply chain process, many steps are constantly being simplified to speed up the flow of supply chain information, business, logistics, and capital flows, and improve the operational efficiency of the supply chain. However, risk transmission has also become more rapid in this process. The impact is more extensive, so financial institutions should increase the speed of credit risk identification and response.

\section{The Causes of Supply Chain Finance Credit Risk}

\subsection{Financial institutions lack information on the actual operation of the supply chain}

Financial institutions do not directly participate in the operation of the supply chain, and mainly rely on the credit level and operating conditions of core enterprises to perform credit rating work. They lack a comprehensive understanding of the operation mechanism of small and medium-sized enterprises and the operation of the entire supply chain. The resulting information asymmetry problem makes Financial institutions are in a passive position. On the one hand, the lack of a formal information recording process for SMEs has led to not much information available to financial institutions, and some companies whitewashed statements and reported false information in order to obtain financing opportunities; on the other hand, financial institutions do not participate in supply chain operations. However, the supply chain operation environment is complex and changeable, causing financial institutions to fail to detect problems and unfavorable changes in supply chain operations in a timely manner.

\subsection{The dominant position of core companies affects the entire supply chain operation}

The realization of supply chain finance requires equal cooperation and mutual benefit among all participating companies in the supply chain. If this level of equality is broken, supply chain finance will have no long-term benefits. But in the supply chain, the core enterprise, as the center of information flow, business flow, capital flow, and logistics, has an obvious dominant position in the overall supply chain. Even if there are common interests, core companies and small and medium-sized companies still have different interest demands. Core companies 
may pursue their own development at the expense of other companies' interests, which will lead to the collapse of the overall supply chain in the long run and create credit risks. In addition, the uneven development level of various enterprises in the supply chain will also affect the overall supply chain operational efficiency and generate credit risks.

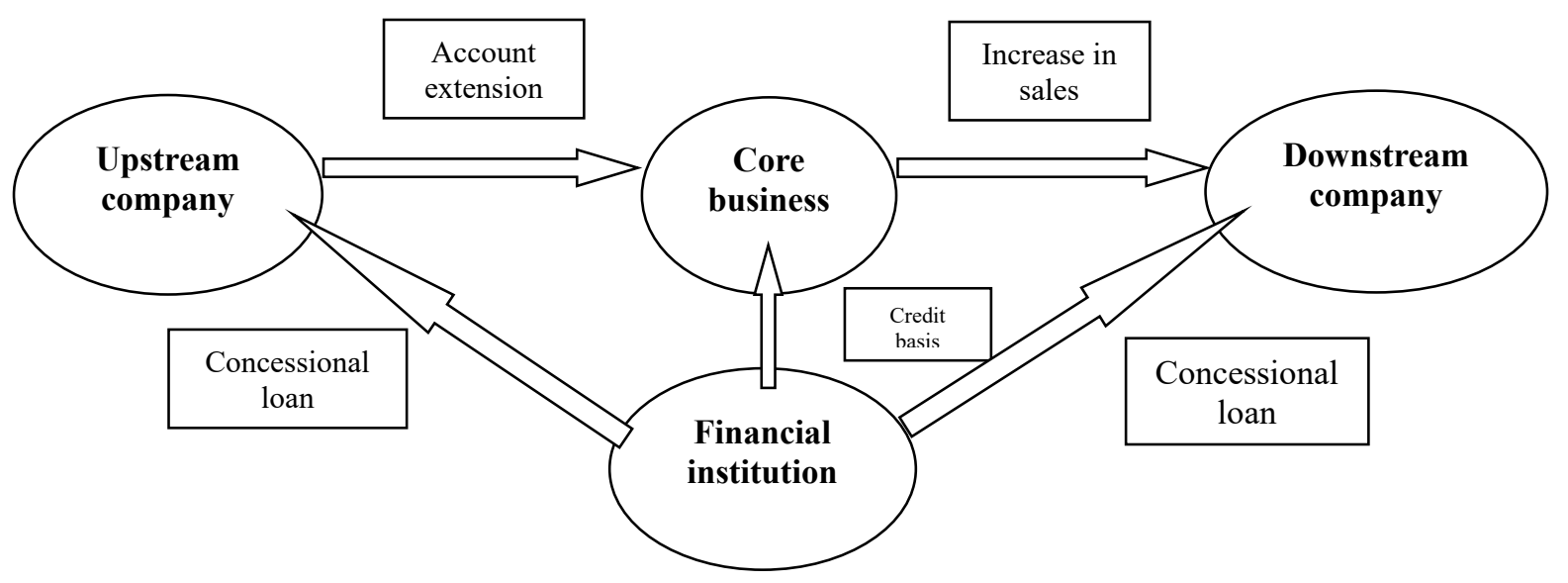

Fig.3. Schematic diagram of supply chain finance centered on core enterprises

\subsection{The uncertainty and linkage of the supply chain itself}

Any risk factor that affects a single enterprise in the supply chain will ultimately affect the smooth operation of the overall supply chain. Therefore, the supply chain itself has great uncertainty. There are many factors that affect the overall supply chain operation, and any adverse impact will be With the delivery of the supply chain, there is a strong linkage. In particular, the speed of product upgrading is getting faster and faster, and the market has put forward higher requirements for business operations. Small and medium-sized enterprises are weak in resisting these risks. The backwardness of any member enterprise may lead to the lag of the overall supply chain. Supply chain financial credit risk. Therefore, financial institutions need to consider all possible influencing factors in risk management, including natural disasters, such as earthquakes, typhoons and other human factors.

\section{Analysis on the Status Quo of Supply Chain Finance Credit Risk Identification and Evaluation}

At present, China's financial institutions mainly rely on existing information and data within financial institutions or obtain financing enterprise information from external consulting agencies and professional groups, and conduct credit ratings on financing enterprises and identify credit risks accordingly. However, this identification method is highly subjective and has less information available. It is difficult to accurately and effectively identify supply chain financial credit risks, which leads to some customers mywho have not met the access conditions to obtain credit qualifications. Assessing supply chain financial credit risk mainly refers to the process of quantifying the possibility of credit risk occurrence and the possible loss once the risk occurs. Commonly used methods or models include expert scoring method,
Z-score scoring model, KMV model, Credit Risk+, etc. However, these models themselves have certain flaws, and the model assumptions are high, the operability is poor in reality, the quantity and quality of data are difficult to guarantee, and it is not easy to apply in practice. The specific reasons for restricting the effective identification and evaluation of supply chain financial credit risks of financial institutions are as follows:

\subsection{Financial institutions lack a systematic credit risk identification and evaluation system}

Some financial institutions do not pay enough attention to credit risk, lack scientific identification and assessment methods, and risk assessment is a mere formality, and there is no complete customer access process and credit line review process. In addition, the professional level and work experience of practitioners also limit the inability of financial institutions to accurately identify credit risks. Some financial institutions associate performance levels with employee salaries, which can easily lead employees to pursue business volume and neglect to examine the level of customer credit ratings.

\subsection{The credit rating system is not detailed enough}

Financial institutions often rely on the credit ratings of core companies and other financing companies to determine whether they meet the credit access conditions. However, some companies have relatively high overall credit ratings, but the indicator details hide a great hidden risk of credit risk. Companies only score high on a certain part of the overall rating system, which drives the overall rating level. This shows that the existing credit rating indicator system is not detailed enough. The targeted analysis of individual indicators and, when necessary, additional review of special evaluation items 
is essential to discover potential risk points.

Take the credit risk evaluation index system of Bank

of China as an example:

Table 1. Bank of China credit risk evaluation index system (excerpted part)

\begin{tabular}{|c|c|c|c|c|}
\hline \multicolumn{5}{|c|}{ Bank of China credit risk evaluation index system (excerpted part) } \\
\hline $\begin{array}{c}\text { Serial } \\
\text { number }\end{array}$ & Indicator name & Calculation formula/evaluation content & $\begin{array}{l}\text { Standard } \\
\text { value }\end{array}$ & $\begin{array}{c}\text { Full } \\
\text { marks }\end{array}$ \\
\hline One & Solvency index & & & 40 \\
\hline 1 & Assets and liabilities & Total liabilities/total assets $\times 100 \%$ & $50 \%$ & 8 \\
\hline 2 & Cash ratio & $\begin{array}{l}\text { (Monetary funds }+ \text { net short-term } \\
\text { investment) } / \text { balance of current liabilities at } \\
\text { the end of the period } \times 100 \%\end{array}$ & $20 \%$ & 6 \\
\hline 3 & Registered capital & & 20 million & 6 \\
\hline 4 & $\begin{array}{l}\text { Registered capital in } \\
\text { place rate }\end{array}$ & $\begin{array}{l}\text { Actual registered capital / amount of } \\
\text { registered capital } \times 100 \%\end{array}$ & $100 \%$ & 4 \\
\hline 5 & Self-sufficiency rate & $\begin{array}{l}\text { (Net assets at the end of the period }+ \\
\text { shareholder loans at the end of the period) / } \\
\text { Project investment completed at the end of } \\
\text { the period } \times 100 \%\end{array}$ & $60 \%$ & 6 \\
\hline 6 & $\begin{array}{l}\text { Cash flow } \\
\text { expectations }\end{array}$ & Operating net cash flow & & 6 \\
\hline 7 & $\begin{array}{l}\text { Expectations for } \\
\text { repayment of bank } \\
\text { loans }\end{array}$ & Reasonable repayment plan & & 4 \\
\hline Two & $\begin{array}{c}\text { Operational } \\
\text { management } \\
\text { indicators }\end{array}$ & & & 28 \\
\hline 8 & $\begin{array}{l}\text { Governance } \\
\text { mechanism }\end{array}$ & $\begin{array}{l}\text { (1) Clear equity structure; } \\
\text { (2) Perfect degree of internal control } \\
\text { mechanism; } \\
\text { (3) The rationality of the organizational } \\
\text { structure; } \\
\text { (4) The degree of perfection of rules and } \\
\text { regulations }\end{array}$ & & 6 \\
\hline 9 & $\begin{array}{l}\text { Market } \\
\text { Competitiveness }\end{array}$ & $\begin{array}{l}\text { (1) The degree of industry control; } \\
\text { (2) The company's own strength; } \\
\text { (3) The advanced nature of the system and } \\
\text { products; } \\
\text { (4) Enterprise development ability }\end{array}$ & & 4 \\
\hline 10 & Leadership & $\begin{array}{l}\text { (1)Leadership, management quality, } \\
\text { technical quality; } \\
\text { (2)Development ability and adaptability; } \\
\text { (3) Unity and cooperation; } \\
\text { (4) Legal concept }\end{array}$ & & 4 \\
\hline 11 & $\begin{array}{l}\text { Qualities of } \\
\text { employees }\end{array}$ & $\begin{array}{l}\text { (1) Cultural quality; } \\
\text { (2) Vocational skills; } \\
\text { (3)Are there regular training }\end{array}$ & & 6 \\
\hline 12 & $\begin{array}{l}\text { Operating income and } \\
\text { operating cost } \\
\text { expectations }\end{array}$ & $\begin{array}{l}\text { (1) Stability of operating income; } \\
\text { (2) Stability of downstream customers and } \\
\text { expectations of target customers; } \\
\text { (3) Upstream customer stability; } \\
\text { (4) Cost composition: whether fixed cost } \\
\text { and variable cost are reasonable }\end{array}$ & & 4 \\
\hline
\end{tabular}




\begin{tabular}{|c|c|c|c|c|}
\hline 13 & Management level & $\begin{array}{l}\text { (1) Construction and implementation of } \\
\text { rules and regulations; } \\
\text { (2)Corporate culture; } \\
\text { (3)Financial management; } \\
\text { (4)Quality, technology and information } \\
\text { management }\end{array}$ & & 4 \\
\hline Three & Prospects & & & 32 \\
\hline 14 & Planning objectives & $\begin{array}{l}\text { (1) Clear development strategy; } \\
\text { (2)The scientific nature of the feasibility } \\
\text { study; } \\
\text { (3)Monitoring of probability, budget and } \\
\text { decision management }\end{array}$ & & 6 \\
\hline 15 & Corporate growth & $\begin{array}{l}\text { (1) The cycle stage of the industry; } \\
\text { (2) Self-growth; } \\
\text { (3) Technology leadership }\end{array}$ & & 6 \\
\hline 16 & Product saturation & $\begin{array}{l}\text { (1) The current product saturation; } \\
\text { (2) Future product saturation }\end{array}$ & & 6 \\
\hline 17 & Government support & $\begin{array}{l}\text { (1)Key support; } \\
\text { (2) General support; } \\
\text { (3) Other situations }\end{array}$ & & 6 \\
\hline 18 & $\begin{array}{l}\text { Background of major } \\
\text { shareholders (holding } \\
\text { more than } 20 \% \text { ) }\end{array}$ & & & 8 \\
\hline Four & Deductible items & & & 0 to -20 \\
\hline 19 & $\begin{array}{l}\text { The ratio of the } \\
\text { amount of loss } \\
\text { involved to net assets }\end{array}$ & $\begin{array}{l}\text { (Major legal proceedings, major accidents } \\
\text { and compensation, major foreign } \\
\text { investment and external guarantee losses) } \\
\text { involved amount / net assets } \times 100 \%\end{array}$ & $0 \%$ & 0 to -10 \\
\hline 20 & $\begin{array}{l}\text { Financial Information } \\
\text { Quality Index }\end{array}$ & $\begin{array}{c}\text { Whether the financial statements are } \\
\text { audited, the degree of authorization of the } \\
\text { audit department, and the quality of the } \\
\text { audit report }\end{array}$ & 0 & 0 to -10 \\
\hline
\end{tabular}

At the same time, Bank of China has also formulated a special indicator system for supply chain finance, including several important indicators such as counterparty credit, transaction relevance, and transaction default. Finally, customer credit ratings are divided into $\mathrm{A}, \mathrm{B}, \mathrm{C}, \mathrm{D}$ based on the scores. Four major categories, as well as $\mathrm{AAA}, \mathrm{AA}, \mathrm{A}, \mathrm{BBB}+, \mathrm{BBB}, \mathrm{BBB}-$, $\mathrm{BB}+, \mathrm{BB}, \mathrm{BB}-, \mathrm{B}+, \mathrm{B}-, \mathrm{CCC}, \mathrm{CC}, \mathrm{C}, \mathrm{D}+$ fifteen credit levels.

If the ability of a customer's management team and the rationality of the management mechanism and the market prospects are not optimistic, and there is even a record of transaction default, but the customer obtains a large amount of revenue through price reduction and other means, adjusts cash flow, and increases short-term investment. Some indicators score very high, and eventually the overall credit rating may be higher, but for financial institutions, there are great hidden risks. At this time, it is not sufficient to rely solely on the final rating results. It is necessary to examine each item one by one to refine the credit rating work.

\subsection{Credit risk is difficult to quantify}

Credit risk is difficult to quantify in two aspects. First, supply chain financial credit risk is affected by many factors. Many risk factors are difficult to measure, and it is impossible to clearly define the relationship between various risk factors. It is relatively subjective and to a large extent. It is still relying on the judgment of professionals; in addition, building a risk assessment model requires a large amount of scientific and reasonable sample data, and the data sources of financial institutions are limited, and most of them are historical data. Many small and medium-sized enterprises even lack basic business data. It is not enough to quantify credit risk and cannot provide sufficient data support for financial institutions to assess credit risk. 


\subsection{The risk assessment model itself has defects}

Currently commonly used risk assessment models have their own shortcomings. For example, the expert scoring method is relatively simple, but it is too subjective, and excessive reliance on the work of experts will also increase the personnel costs of financial institutions; the KMV model is not for the company's default Risk prediction is relatively accurate, but it is only applicable to listed companies, and does not consider the impact of factors such as interest rate risk. The assumptions of some models are too ideal, and the actual market environment deviates greatly from the assumptions, and the models cannot be truly applied to reality.

\section{Suggestions for coping with financial credit risks in supply chain}

\subsection{Improve and refine the credit rating system}

Financial institutions should refine the credit rating system based on the development of the company and the level of the industry, and examine the indicators in a targeted manner. In particular, it is necessary to select key and sensitive indicators for individual assessment. The selection of indicators should be based on scientific basis, and can be combined with financing enterprises. Replace different indicators for your own situation. For companies with high credit ratings, check their indicator details to ensure that the potential risks reflected by each important indicator are within the acceptable range of financial institutions, and then grant credit lines. At the same time, the evaluation indicators should not be limited to historical financial information. Non-financial information such as the company's future development prospects and management structure should also be fully considered to explore potential problems.

Take the credit rating indicator system of the Bank of China mentioned above as an example. If a company raises its overall credit rating by improving its solvency indicators and operating income and other short-term data, financial institutions need to specifically examine each indicator item, or even compare each indicator. The breakdown of indicators is divided into specific analysis. For example, market competitiveness can be subdivided into specific regions, and the specific market competition environment of a certain region can be broken down. If it collapses, will it have a huge impact on the operation of the enterprise; for another example, the degree of government support can be subdivided into specific areas. 1. The support status of the product. Analyzing an indicator alone or subdividing specific indicators can more effectively find potential risk points and have a more in-depth and comprehensive understanding of customer credit status.

\subsection{Improve the supply chain financial credit database}

Financial institutions can establish a corporate credit database in a targeted manner based on the characteristics of the enterprise. Financial institutions should, under the premise of fully considering the particularities of the industry or enterprise business, selectively select key data information and archive them. With the development of technology, financial institutions can establish online information sharing platforms to improve the efficiency of obtaining information. Of course, the establishment of a database requires the support of government agencies or related professional groups. Without violating the principle of confidentiality, more information should be made public and transparent.

\subsection{Cooperate with multiple credit risk assessment models}

Since each risk assessment model has its own shortcomings, and has different focuses and different risks, it is impossible to identify or evaluate all potential credit risks of supply chain finance by relying on only one method. Therefore, by using a variety of credit risk identification and evaluation models, comprehensively considering the particularity of the industry and the focus of various models, and choosing the best model combination, credit risks can be more comprehensively identified and evaluated. On the premise that cost-benefit analysis is feasible, specialized improvements to existing models or the application of special models developed by ourselves are also conducive to accurately identifying and assessing credit risks.

\subsection{Dynamic monitoring of credit risk}

Regular monitoring of credit risk is only a static assessment of a single point in time, but the credit risks that exist at different times in the supply chain are different, and the risk spreads quickly. If the potential risk points cannot be discovered in time, it may cause serious consequences in a short period of time. Realize the dynamic risk monitoring, and set up a tracking evaluation system to help financial institutions screen suspicious transactions in a timely manner, predict the future trading trend of the supply chain, lock down risks, and increase prevention and control measures for special risk points. Of course, because dynamic monitoring requires more manpower and material resources, financial institutions should fully consider relevant costs in advance in the process of realizing dynamic management, especially for the low probability of occurrence or even if it does not have undue impact on the financial institution Financial institutions should consider the necessity of dynamic management and determine the most appropriate degree of dynamics.

\subsection{Improve the risk management system and strengthen personnel quality education}

Financial institutions should establish systematic and complete rules and regulations and unified standards for risk management, especially for the emergence of new products, the latest market trends, new national policies, 
changes in international forms, etc., which are prone to supply chain financial credit risks. In the event of an event, financial institutions should set up adequate risk early warning systems and response measures. In addition, the establishment of a professional talent training mechanism and fixed-point training for problems that may arise in practice require practitioners to not only be familiar with theoretical knowledge, but also have the ability to combine actual market insights into potential risk points. Strengthening personnel quality education is to support the effective identification of financial institutions. Assess the protection of credit risk.

\section{Conclusion}

Supply chain is the product of strengthened cooperation between enterprises, and supply chain finance is the product of enterprises actively seeking capital help for mutual benefit and win-win results. The resulting credit risk is affected by the characteristics of the supply chain and has the characteristics of fast transmission speed and strong linkage. Only through strict credit rating screening, comprehensive and meticulous evaluation process, and rational use of big data, information sharing platforms, etc. Advanced technology, increasing transaction transparency, and realizing dynamic risk management can realize effective management of credit risk, ensure the continuous financial support of the supply chain, realize the long-term development of the supply chain, and create value for financial institutions and all member companies in the supply chain.

\section{References}

1. J. Hallikas, V.M. Virolainen, M. Tuominen., Risk analysis and assessment in network environments: A Dyadic Case Study, [J]. Int J Prod Econ, 78, 44-55 (2002)

2. Y.Z. Yang, On the Risk Prevention of Commercial Bank Supply Chain Finance, [J]. Financ. Forum, 142, 44-47 (2007)

3. S.J. Fan, Optimization of Logistics Finance Operation Mode and Research on Risk Management, [J]. China Bus. Trade, 545, 146-147 (2012)

4. J.S. Huang, H. Song, X.H. Song, Research on the Methods of Identifying and Evaluating the Risks of Supply Chain Finance Loans, [J]. Financ. Theory Pr., 415, 50-53 (2014)

5. F.Z. Fan, G.Q. Su, X.Y. Wang, Research on Credit Risk Evaluation and Risk Management of Small and Medium-sized Enterprises under Supply Chain Finance Mode, [J]. J CUFE, 34-43 (2017)

6. G.R. Li, Y.X.Guan, Y. Huang, The characteristics, analysis framework and management countermeasures of supply chain finance credit risk, [J]. J Com. Econ., 800, 169-171 (2020)

7. X.J. Chu, P.F. Li, Research on the Prevention and Control Mechanism of Supply Chain Finance Credit Risk Proliferation, $[\mathrm{J}]$. J Financ. Dev. Res., 422, 